\title{
Changes in drought tolerance of Pinus radiata in Chile associated with provenance and breeding generation
}

\author{
Sergio E. Espinoza ${ }^{1} \cdot$ Carlos R. Magni $^{2} \cdot$ Rómulo E. Santelices $^{1} \cdot$ Milǒs Ivković $^{3}$. \\ Antonio M. Cabrera ${ }^{1}$
}

Received: 1 December 2014 / Accepted: 17 June 2015 /Published online: 30 November 2015

(C) INRA and Springer-Verlag France 2015

\begin{abstract}
Key message In Chile, breeding radiata pine for growth has led to drifts in the degree of drought tolerance of the seedlings. Interior provenances gained a larger tolerance to drought after three breeding generations as shown by larger survival and root/shoot ratio under water shortage, while coastal provenance displayed an opposite trend.

- Context Given that rainfall is predicted to decrease and to affect establishment and early survival of radiata pine (Pinus radiata D. Don) in Chile, there is a need to identify more drought tolerant genotypes at seedling stage.

- Aims The aim of this study was to test whether provenances of $P$. radiata originating from interior or from coastal provenances, displayed different responses to short-term water shortage, and whether these responses differed from the first to the third breeding generation.
\end{abstract}

\section{Handling Editor: Andrew Merchant}

Contribution of the co-authors Sergio Espinoza was responsible for data collection, analysis, and interpretation of the results. He was also responsible for the writing of the paper.

Carlos Magni contributed ideas that initiated this work and helped in reviewing the paper.

Rómulo Santelices contributed ideas and reviewed the final manuscript. Milǒs Ivković contributed in editing the paper and reviewed the final manuscript.

Antonio Cabrera contributed ideas and commented on the methodology and earlier drafts of the manuscript.

Sergio E. Espinoza

espinoza@ucm.cl

\footnotetext{
Universidad Católica del Maule, Talca, Chile

Universidad de Chile, Santiago, Chile

CSIRO, Canberra, Australia
}

- Methods Three generations of breeding families from two sites in Central Chile were compared. The seedlings were grown during 100 days and subjected to two watering regimes for 45 days. Survival, growth, and biomass allocation to roots and shoots were recorded.

- Results The two provenances displayed different responses to drought. Biomass allocation to shoots and survival were significantly reduced by water shortage. The first generation seedlings from the coastal provenance displayed a larger survival rate when exposed to water shortage (i.e., $60 \%$ ); this rate decreased in the following breeding generations. On the contrary, the survival rate increased from the first to the third generation in the interior provenance.

- Conclusions We observed an important local adaptation to water shortage in the interior provenance. This response may be due to the fact that parent tree populations of the interior provenance have successfully adapted to sites with periodic drought.

Keywords Water shortage $\cdot$ Radiata pine $\cdot$ Biomass allocation $\cdot$ Adaptation $\cdot$ Population $\cdot$ Tree-breeding

\section{Introduction}

Plant species introduced outside their native ranges may face very different environmental conditions than those in their native habitats. Soil properties and hydrology can differ. Successful establishment and subsequent spread depends on the ability to tolerate and adapt to the new environmental conditions. Radiata pine (Pinus radiata D. Don) is the world's most extensively planted exotic softwood, with over four million hectares planted worldwide (Mead 2013). The species was introduced in Chile during the 1890s (Camus 2006) and is now the most extensively planted conifer in the country. The 
earliest records show radiata pine was introduced in Chile with only one consignment (Lewis and Ferguson 1993); however, information about where the original planting stock was harvested in the native range is not available. No new introduction was registered until the beginning of genetic selection programs during the late 1980s. The species was initially established in coastal areas (Albert 1900), but soon after, the process of expansion into other sites (i.e., interior sites) of the country was undertaken. Once established in new environments, radiata pine plantations experienced adaptation to local conditions, which was probably favored by the high plasticity of the species (Zobel and Talbert 1984; Espinoza et al. 2013; Mead 2013), resulting in an increased ability to succeed in new environment. According to Schlichting (2004) and Pigliucci et al. (2006), differing selection pressure on novel phenotypes could lead to local adaptation.

Breeding of the species has started in the 1970s and has been directed towards characters such as volume, form, and wood density. Currently, breeding programs are producing the third generation of individuals, and there is no clear intention to include drought tolerance traits within their breeding objectives. Radiata pine can be considered to have a high degree of drought tolerance (Heth and Kramer 1975; Mead 2013) as it has the capability to change its biomass allocation when facing water deficits, allocating more biomass to the roots at the expense of the shoots (Espinoza et al. 2013). However, the projected increase in summer drought (CONAMA 2006) creates the necessity of obtaining planting material suitable for drought-prone sites. Radiata pine breeding in Chile has been successful on improving growth and form traits; however, little is known about the effects of the introduction, artificial selection and three generations of breeding, on the morphological changes, and survival induced by water shortage during the initial developmental stages of this species.

There are several papers investigating the possible consequences of selection for growth on wood density in radiata pine (Cown et al. 1992; Li and Wu 2005; Bouffier et al. 2009); however, no studies have investigated the change of survival and biomass allocation in radiata pine trees that underwent selection for growth. The aim of this experiment was to test whether provenances of $P$. radiata originating from interior and coastal sites and from the first to the third breeding generation show different responses to water shortage. We hypothesized that breeding for growth and adaptation to local conditions has changed the degree of drought tolerance in interior provenance when passing from the first to the third breeding generation. To test this hypothesis, a nursery experiment was carried out with the aforementioned provenances and breeding generations, testing how two different water levels affected biomass allocation, growth, and survival in young $P$. radiata seedlings.

\section{Materials and methods}

\subsection{Plant material}

Two provenances of radiata pine were selected, one from an interior and one from a coastal site in Central Chile. A description of the climatic parameters of these two sites is given in Table 1. Seeds from 98 parents (i.e., 49 interior and 49 coastal) were obtained from the following three sources:

1) Thirty-five open-pollinated families obtained from plus trees in plantation in coastal ( 7 families) and interior ( 28 families) sites (i.e., the first generation of breeding)

2) Forty-eight open-pollinated families from coastal (19 families) and interior (29 families) sites obtained from two different open-pollinated seed orchards (i.e., the second generation of breeding)

3) Fifteen control-pollinated families from coastal (13 families) and interior ( 2 families) sites obtained from one control-pollinated seed orchard (i.e., the third generation of breeding)

These families were selected on the basis of their inclusion in the current Forestal Mininco S.A. breeding program.

\subsection{Experimental conditions}

The study was conducted in a nursery under natural light and temperature conditions. Local micro-environmental conditions were strictly controlled (i.e., wind, position of the trays with respect to the solar angle, and drift of water mist), in order to allow all seedlings to receive the same growth conditions, except for the watering regime. Seeds were sown in $140 \mathrm{~cm}^{3}$ pots with a mixture of composted bark of radiata pine and perlite $(8: 2 v / v)$, combined with a slow-release fertilizer (Basacote $^{\mathrm{TM}}$ plus $6 \mathrm{M}$, at $3 \mathrm{~kg} \mathrm{~m}^{3}$ ) on 15 Nov. 2012 (day 0). After germination, seedlings from each family were arranged in a split-plot design, with watering regime as the whole plot and family nested within provenance as the sub-plots. Two provenances (49 families per provenance) and two watering treatments were used. The two watering treatments, wellwatered (WW) and water shortage (WS), were applied to 98 families $\times 3$ replicates $\times 11$ seedlings per family (i.e., 6,468 seedlings in total) (Fig. 1).

The experiment was divided into two treatment phases. Firstly, a growing phase (watering to container capacity, average temperature, and relative humidity between $14-20^{\circ} \mathrm{C}$ and $60-70 \%$, respectively) that lasted until the plants were 100 days old. In this phase, seedlings were watered daily according to the nursery prescriptions (i.e., twice per day). At the end of this growing phase, the seedlings had a mean height of $22.2 \pm 3.7 \mathrm{~cm}$ and a stem diameter of $2.6 \pm 0.3 \mathrm{~mm}$. Secondly, after this growing phase, plants were submitted to 
Table 1 Origin of radiata pine investigated: soil and climatic features of their zones of origin

\begin{tabular}{|c|c|c|c|c|c|c|c|c|c|}
\hline \multirow[t]{2}{*}{ Provenance } & \multirow{2}{*}{$\begin{array}{l}\text { Annual } \\
\text { rainfall } \\
(\mathrm{mm})\end{array}$} & \multirow{2}{*}{$\begin{array}{l}\text { Summer relative } \\
\text { humidity }(\%)^{\mathrm{a}}\end{array}$} & \multirow{2}{*}{$\begin{array}{l}\text { Summer maximum } \\
\text { temperature }\left({ }^{\circ} \mathrm{C}\right)^{\mathrm{a}}\end{array}$} & \multirow{2}{*}{$\begin{array}{l}\text { Winter } \\
\text { rainfall } \\
(\mathrm{mm})^{\mathrm{b}}\end{array}$} & \multirow{2}{*}{$\begin{array}{l}\text { Parent } \\
\text { material }\end{array}$} & \multirow{2}{*}{$\begin{array}{l}\text { Water holding } \\
\text { capacity (mm) }\end{array}$} & \multicolumn{2}{|l|}{ Location } & \multirow{2}{*}{$\begin{array}{l}\text { Number of } \\
\text { families }\end{array}$} \\
\hline & & & & & & & $\begin{array}{l}\text { Latitude } \\
\text { (S) }\end{array}$ & $\begin{array}{l}\text { Longitude } \\
\text { (W) }\end{array}$ & \\
\hline Interior & 1100 & $63-65$ & $26.1-28.6$ & $553-619$ & Sandy & 100 & $37^{\circ} 31^{\prime}$ & $72^{\circ} 04^{\prime}$ & 49 \\
\hline Coastal & 1300 & $77-80$ & $19.4-23.9$ & $588-713$ & $\begin{array}{l}\text { Granitic- } \\
\text { metamor- } \\
\text { phic }\end{array}$ & 400 & $38^{\circ} 14^{\prime}$ & $73^{\circ} 17^{\prime}$ & 49 \\
\hline
\end{tabular}

${ }^{\text {a }}$ Summer relative humidity and maximum temperature pertain to January and February

${ }^{\mathrm{b}}$ Winter rainfall pertain to June, July, and August

two watering regimes (WW and WS treatments) for 45 days (145 days growth in total). This growth period insured that the rooting media had not excessively limited root development and that all seedlings were in the same ontogenic state (i.e., before the formation of dwarf shoots). According to Poorter et al. (2012a), young plants are initially not affected by pot size, but as they age, the pot size effect becomes more pronounced. In this study, P. radiata seedlings were raised for 5 months instead of the usual 8-month growing period commonly used in $P$. radiata in forestry nurseries.

The severity of the watering regimes was based on predawn plant water potentials $\left(\psi_{\mathrm{pd}}\right)$. In the $\mathrm{WW}$ treatment, seedlings were watered daily to container capacity to maintain a $\psi_{\text {pd }}$ of $-0.5 \pm 0.1 \mathrm{MPa}$, as measured with a pressure chamber. Temperature and relative humidity averaged $19{ }^{\circ} \mathrm{C}$ and $70 \%$, respectively. In the WS regime, three 13-day cycles of withholding of water, plus 2 days of watering between each cycle, were applied. The 2-day watering period was not applied in the last cycle. Seedlings reached a $\psi_{\text {pd }}$ of $-1.5 \pm 0.1 \mathrm{MPa}$ on average. Temperature and relative humidity averaged $22{ }^{\circ} \mathrm{C}$ and $59 \%$, respectively. During this period, the water supply was withdrawn until the water content of each tray (with 88 containers of $140 \mathrm{~cm}^{3}$ ) reached $\sim 30 \%$ of container capacity, determined by weighing a subsample of trays. This watering
Fig. 1 Experimental split-plot layout for two watering regimes, two populations, and three breeding generations (families and provenances were randomized within replications, each containing the 98 families)

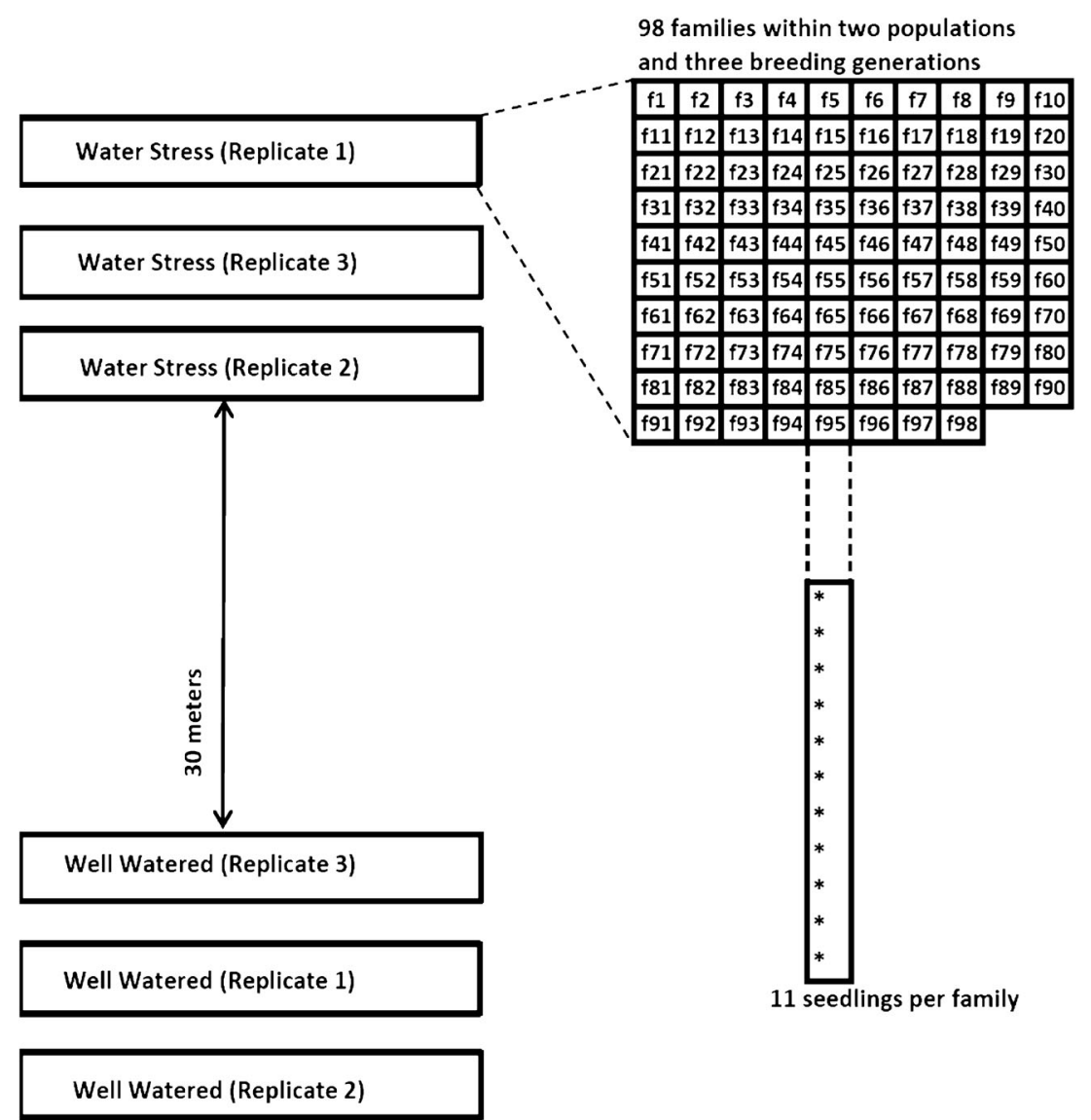


level was maintained approximately constant until the end of the stress period (Espinoza et al. 2013).

\subsection{Assessments}

Before the start of water restriction (day 100), total height $(H)$ and root collar diameter $(D)$ were measured on 30 seedlings in all 98 families. Biomass harvest was made 45 days after the beginning of the water stress cycles, when seedlings were 145 days old. After that, all seedlings were harvested and then oven-dried at $70{ }^{\circ} \mathrm{C}$. Due to the amount of samples $(6,468$ seedlings $\times 3$ components of biomass each $=19,000$ ca.) and to insure the complete drying of seedlings, these were oven-dried for 5 days instead of $48 \mathrm{~h}$. $H$ and $D$ were also measured and three fractions (i.e., roots, needles, and stems) were weighed ( $\pm 0.01 \mathrm{~g})$, giving the root dry weight (RDW), the needle dry weight (NDW), the stem dry weight (SDW), and the total dry weight (TDW). The following variables were subsequently derived: the root/shoot ratio $(\mathrm{RSR}=\mathrm{RDW} /(\mathrm{SDW}+$ $\mathrm{NDW})$ ) and the height/diameter ratio $(\mathrm{HDR}=H / D)$. Survival (SUR) was also measured at the end of the experiment as a categorical trait (i.e., $1=$ alive seedling, $0=$ dead seedling), in the 6,468 seedlings of the experiment.

\subsection{Statistical analysis}

Size traits (i.e., $H, D, \mathrm{HDR}$ ), biomass traits (i.e., TDW, RDW, SDW, NDW, RSR), and survival were analyzed with the general linear model approach (GLM) to analysis of variance, with type III sum of squares, using SAS software (SAS 1999). Comparisons between the two groups for categorical variables (i.e., SUR) were done using a chi-square test. Prior to the analysis, the data were examined and conformed to the normality and homogeneity of variance assumptions required for the analysis of variance. The model terms were fitted according to the hierarchical design of the experiment, considering breeding generation as nested within provenances. The model was

$$
\begin{aligned}
Y_{i j k l}= & \mu+W_{i}+P_{j}+G(P)_{k j}+W_{i} \times P_{j}+W_{i} \\
& \times G(P)_{k j}+e_{i j k l},
\end{aligned}
$$

where $Y_{i j k l}$ is the observed phenotypic measurement (growth, survival, and biomass traits), $\mu$ is the overall mean, $W_{i}$ is the fixed effect of $i$ th watering regime (WW and WS), $P_{j}$ is the fixed effect of $j$ th provenance (interior and coastal provenances), $G(P)_{k j}$ is the random effect of the $k$ th breeding generation (first to third) nested within the $j$ th provenance, $W_{i} \times P_{j}$ is the interaction between $i$ th watering regime and the $j$ th provenance, $W_{i} \times G(P)_{k j}$ is the interaction between $i$ th watering regime and the $k$ th breeding generation nested within the $j$ th provenance, and $e_{i j k l}$ is the experimental random error. A significant effect of the water stress treatment in this analysis indicates the existence of phenotypic changes in response to drought for the trait considered, and a significant genotype $\times$ environment interaction (i.e., interaction $W_{i} \times G(P)_{k j}$ of the model), indicates the existence of differences among breeding generations within provenances for those changes. Differences in initial seedlings size (i.e., the day $100 \mathrm{D}$ and $H$ ) were tested with a $t$ test.

For the biomass allocation analysis, we performed an allometric analysis through the regression of the natural logarithms of each biomass component (RDW and SDW + NDW) (Poorter and Nagel 2000). The following classical allometric equation (Pearsall 1927) was used:

$Y=\alpha X^{\beta}$

where $\beta$ is the allometric exponent, $\alpha$ is the allometric coefficient, $Y$ is the root (i.e., RDW) component, and $X$ is the shoot (i.e., sum of the SDW + NDW) component. The parameter $\beta$ has a biological and mathematical meaning, i.e., the ratio of the relative growth rates of roots relative to that of shoots. The allometric equation was log-transformed to yield a simple linear relationship.

$\log (Y)=\log (\alpha)+\beta \log (X)$,

where the allometric exponent becomes the slope and the log of the allometric coefficient is the intercept. Because the emphasis in this study was on comparing the slopes of log-log analyses against each other or a (null model) slope of 1.0, we used major axis (MA) regressions to calculate allometric slopes. MA log-log slopes between provenances and breeding generations were compared against each other using routines found in the (S)MATR package of Falster et al. (2003).

Changes in allocational patterns were assessed by comparison of the slopes and intercepts corresponding to different watering levels (Schlichting and Pigliucci 1998). When, for a given breeding generation within provenance, a strong linear relation between biomass compartments existed and the two lines of regression corresponding to the two water treatments overlapped, the slope of those lines will differ only if the water stress treatment caused significant changes in the relative growth rates of shoots (stem + needles) and roots. Following Samson and Werk (1986) and Klinkhamer et al. (1990), $F$ tests were used to investigate proportionality of allocation and the influence of water on these relationships. This was done using RDW as the dependent variable $(Y)$ and SDW as the covariate $(X)$ in the GLM. 


\section{Results}

\subsection{Effects of water stress on growth and survival}

The watering regime, provenance, the breeding generation within the provenance, and the respective interactions had significant effects on most traits under consideration (Table 2). Growth, survival and biomass in the different fractions (root, needles, and stem) were different for the two watering levels, with clear reductions in all traits in stressed seedlings in comparison to the well-watered ones (Table 3). There were significant watering $\times$ provenance interactions in some of the traits $(p<0.01)$. In the WS treatment, the relationship between SUR and the generation number is positive in the interior provenance and negative in the coastal provenance (Table 3), i.e., when interior provenance seedlings pass from the first to the third breeding generation, they increase SUR. Seedlings from the interior provenance are taller and heavier than those of the coastal provenance both before and after the water shortage. These differences were also observed in the interactions between watering $\times$ generation within provenances. In this respect, seedlings from the interior provenance and the first breeding generation showed the highest $D, H$, HDR, RDW, NDW, SDW, and TDW when exposed to water shortage, while the third breeding generation seedlings showed the highest RSR. As expected, SUR was $100 \%$ for both provenances in WW treatment.

In general, there was a shift in growth, survival, and biomass allocation from first to third breeding generation, with seedlings from third generation coming from interior provenance being shorter, with smaller diameters and higher root/shoot ratios in relation to the first generation seedlings from the same provenance. The opposite tendency was observed in coastal provenance, in which, the third generation seedlings are larger than the first generation ones. They also allocate more biomass to roots (Table 3). SUR was also different for the two water treatments, provenance and breeding generations, with the latter being clearly affected by the water stress imposed $(p<0.01)$. It is noteworthy to mention that interior provenance increased in survival from the first to the third generation, while the opposite was observed in coastal population (Table 3).

\subsection{Effects of water stress on biomass allocation}

The allometric analysis showed that slopes and intercepts for the regression between $\log _{10}$ (RDW) and $\log _{10}$ (SDW + NDW) for both watering treatments analyzed were different $(p<0.001)$. Water shortage induced a change in the dry shoot biomass in relation to dry root biomass for the two provenances (Fig. 2), and breeding generations (Fig. 3), with a trend to increase differences in slope when passing from the first to the third breeding generation. Three generations of breeding
Table 2 Significance of the effect of watering treatment, provenance, the interaction between watering and provenance, and the interaction between watering and generation provenance on the variance of eight morphological traits and survival measured in $P$. radiata, according to multivariate analyses of variance

\begin{tabular}{lcccc}
\hline Trait & \multicolumn{4}{l}{$F$ value and significance level } \\
\cline { 2 - 5 } & Watering & Provenance & $W \times P$ & $W \times G(P)$ \\
\hline$D$ & $1534^{*}$ & $3.8^{*}$ & $4.7 \mathrm{~ns}$ & $4.6^{*}$ \\
$H$ & $1932^{*}$ & $37.2^{*}$ & $2.2 \mathrm{~ns}$ & $2.8 \mathrm{~ns}$ \\
HDR & $114^{*}$ & $4.3^{*}$ & $4.6^{*}$ & $4.5^{*}$ \\
RDW & $1143^{*}$ & $2.0^{*}$ & $8.1 \mathrm{~ns}$ & $7.9^{*}$ \\
NDW & $889^{*}$ & $2.8^{*}$ & $9.6 \mathrm{~ns}$ & $9.4^{*}$ \\
SDW & $512^{*}$ & $4.1^{*}$ & $10.5^{*}$ & $10.3^{*}$ \\
TDW & $962^{*}$ & $2.9^{*}$ & $13.4^{*}$ & $13.1^{*}$ \\
RSR & $38.6^{*}$ & $4.3 \mathrm{~ns}$ & $3.1 \mathrm{~ns}$ & $3.0^{*}$ \\
SUR & $1637^{*}$ & $4.8^{*}$ & $4.8^{*}$ & $26.6^{*}$ \\
\hline
\end{tabular}

$D$ root collar diameter (mm), $H$ total height $(\mathrm{cm}), H D R$ height/diameter ratio, $R D W$ roots dry weight $(\mathrm{mg}), N D W$ needle dry weight $(\mathrm{mg}), S D W$ shoot dry weight $(\mathrm{mg}), T D W$ total dry weight $(\mathrm{mg}), R S R$ root/shoot ratio, SUR survival, $n s$ not significant

${ }^{*} p<0.01$

decreased allocation to roots while increasing allocation to shoots, i.e., their allometric exponents were significantly smaller than one (i.e., $0.210<\beta<0.708$ ). Also, the interaction between RDW and the watering regime with $\log$ of SDW as a covariate were significant for provenances and generations, which indicates that trajectories of biomass allocation were altered by watering regime and the covariate.

\section{Discussion}

\subsection{Effects of water stress on growth and survival}

The two examined $P$. radiata provenances revealed significant differences in their response to water shortage with respect to needle and root dry weight, survival, and growth, especially in the third generation seedlings from interior provenance, which when exposed to water shortage had a better survival compared with the third generation seedlings from coastal provenance. Parent trees of the interior provenance seedlings developed on sites characterized by a low water holding capacity and high vapor pressure deficit in comparison with parent trees of the coastal provenances, which developed in coastal sites (Huber and Trecaman 2002). These harsh conditions generated the driving force behind selection for drought tolerance in the interior provenance because before the massive plantations in the early 1900 s, seedlings naturally germinated in early spring faced with their first hot and dry season. This provenance is subjected to lower water availability during 
Table 3 Effects of the interaction between water treatments, provenances and breeding generation. Means \pm standard errors

\begin{tabular}{|c|c|c|c|c|c|c|}
\hline \multirow[t]{2}{*}{ Traits } & \multicolumn{3}{|l|}{ Interior } & \multicolumn{3}{|l|}{ Coastal } \\
\hline & First & Second & Third & First & Second & Third \\
\hline \multicolumn{7}{|l|}{ Well watered } \\
\hline$H(\mathrm{~cm})$ & $31.0 \pm 0.11$ & $26.0 \pm 0.12$ & $25.5 \pm 0.35$ & $25.3 \pm 0.20$ & $26.8 \pm 0.11$ & $26.4 \pm 0.17$ \\
\hline$D(\mathrm{~mm})$ & $3.80 \pm 0.01$ & $3.47 \pm 0.01$ & $3.41 \pm 0.05$ & $3.33 \pm 0.02$ & $3.46 \pm 0.01$ & $3.45 \pm 0.01$ \\
\hline HDR & $8.21 \pm 0.03$ & $7.55 \pm 0.05$ & $7.55 \pm 0.14$ & $7.63 \pm 0.08$ & $7.81 \pm 0.04$ & $7.71 \pm 0.07$ \\
\hline RDW (mg) & $1.31 \pm 0.01$ & $1.07 \pm 0.00$ & $0.92 \pm 0.01$ & $0.95 \pm 0.01$ & $1.04 \pm 0.00$ & $1.07 \pm 0.00$ \\
\hline NDW (mg) & $1.63 \pm 0.01$ & $1.25 \pm 0.00$ & $1.06 \pm 0.02$ & $1.16 \pm 0.01$ & $1.26 \pm 0.00$ & $1.29 \pm 0.01$ \\
\hline SDW (mg) & $0.95 \pm 0.00$ & $0.64 \pm 0.00$ & $0.63 \pm 0.01$ & $0.59 \pm 0.01$ & $0.67 \pm 0.00$ & $0.65 \pm 0.00$ \\
\hline TDW (mg) & $3.89 \pm 0.02$ & $2.96 \pm 0.01$ & $2.61 \pm 0.04$ & $2.70 \pm 0.02$ & $2.97 \pm 0.01$ & $3.01 \pm 0.01$ \\
\hline RSR & $0.57 \pm 0.00$ & $0.57 \pm 0.00$ & $0.56 \pm 0.02$ & $0.56 \pm 0.02$ & $0.56 \pm 0.00$ & $0.57 \pm 0.03$ \\
\hline SUR (\%) & $100 \pm 0.00$ & $100 \pm 0.00$ & $100 \pm 0.00$ & $100 \pm 0.00$ & $100 \pm 0.00$ & $100 \pm 0.00$ \\
\hline \multicolumn{7}{|l|}{ Water stress } \\
\hline$H(\mathrm{~cm})$ & $26.5 \pm 0.09$ & $21.4 \pm 0.12$ & $21.3 \pm 0.35$ & $20.0 \pm 0.20$ & $21.9 \pm 0.11$ & $22.0 \pm 0.17$ \\
\hline$D(\mathrm{~mm})$ & $2.84 \pm 0.01$ & $2.71 \pm 0.01$ & $2.72 \pm 0.05$ & $2.62 \pm 0.02$ & $2.66 \pm 0.01$ & $2.69 \pm 0.01$ \\
\hline HDR & $9.43 \pm 0.04$ & $7.97 \pm 0.05$ & $7.93 \pm 0.14$ & $7.70 \pm 0.08$ & $8.31 \pm 0.04$ & $8.25 \pm 0.07$ \\
\hline RDW (mg) & $0.57 \pm 0.00$ & $0.52 \pm 0.00$ & $0.53 \pm 0.01$ & $0.44 \pm 0.01$ & $0.51 \pm 0.00$ & $0.54 \pm 0.00$ \\
\hline NDW (mg) & $0.80 \pm 0.00$ & $0.70 \pm 0.00$ & $0.65 \pm 0.02$ & $0.58 \pm 0.01$ & $0.68 \pm 0.00$ & $0.73 \pm 0.01$ \\
\hline SDW (mg) & $0.49 \pm 0.00$ & $0.38 \pm 0.00$ & $0.38 \pm 0.01$ & $0.30 \pm 0.01$ & $0.38 \pm 0.00$ & $0.40 \pm 0.00$ \\
\hline TDW (mg) & $1.86 \pm 0.01$ & $1.60 \pm 0.01$ & $1.56 \pm 0.04$ & $1.32 \pm 0.02$ & $1.57 \pm 0.01$ & $1.67 \pm 0.01$ \\
\hline RSR & $0.46 \pm 0.02$ & $0.51 \pm 0.02$ & $0.55 \pm 0.07$ & $0.54 \pm 0.02$ & $0.50 \pm 0.00$ & $0.50 \pm 0.03$ \\
\hline SUR (\%) & $28.3 \pm 1.60$ & $51.5 \pm 2.10$ & $50.0 \pm 6.20$ & $60.2 \pm 3.50$ & $47.1 \pm 1.70$ & $40.2 \pm 2.50$ \\
\hline
\end{tabular}

$D$ root collar diameter, $H$ total height, $H D R$ height/diameter ratio, $R D W$ roots dry weight, $N D W$ needle dry weight, $S D W$ stem dry weight, $T D W$ total dry weight, $R S R$ root/shoot ratio, $S U R$ survival winter and high temperatures and vapor pressure deficit during summer (Table 1). It may be possible that drought tolerance of interior provenance be more strongly related to climatic variables associated with water holding capacity, evaporative demand during summer than to precipitation, and to stomatal control and allocation of biomass to roots. Espinoza et al. (unpublished data) in a 2-year-old field trial established in a sandy soil site in Central Chile with less than $50 \mathrm{~cm}$ of water holding capacity found that interior provenance had a lower stomatic conductance and higher allocation of biomass to the belowground organs. This allows us to speculate that the novel environmental conditions that were experienced by radiata pine in interior sites in its early generations could have lead this provenance to local adaptation by allocating more biomass to the roots as a strategy to conserve water more efficiently.

Results of the present study showed that the third breeding generation seedlings from interior provenance submitted to water stress have a survival rate which is more than $25 \%$ superior to the third breeding generation seedlings from coastal provenance. Seedlings of the interior provenance probably improved their survival by decreasing transpiratory demand and water transport (i.e., less NDW and SDW). It can be questioned whether the higher survival of the interior provenance could be attributed to the fact that seedlings of this provenance were in general larger than the coastal ones.
However, as can be seen in Table 3, they showed a decrease in $H$ from the first to the third breeding generation and allocate less biomass to the transporting and photosynthetic organs. Interior provenance also had less total mass under drought stress, as evidenced by a decrease in TDW with increasing generations of breeding, while seedlings from coastal provenance had the opposite, which indicates that they can continue to grow in the face of drought stress until they put themselves at greater risk of mortality due to an overall larger respiratory demand or greater transpiration.

Seedlings from coastal provenance had a better survival in water stress conditions in the early breeding generations because they were small (Table 3) and had more water per gram of plant. However, seedlings from interior provenance had an increased survival when passing from one breeding generation to the next, despite being taller in the first breeding generation under the water stress condition, and having depleted the pot water more quickly because of their higher total transpiration (Table 3). According to Poorter et al. (2012b), if large plants are present in relatively small pots under high evaporative demand, this leads to a very quick depletion of the available water, giving hardly any time for the plant to acclimate physiologically and morphologically.

We argue that, in the context of rapid climate change, local adaptation has been a crucial determinant of interior 

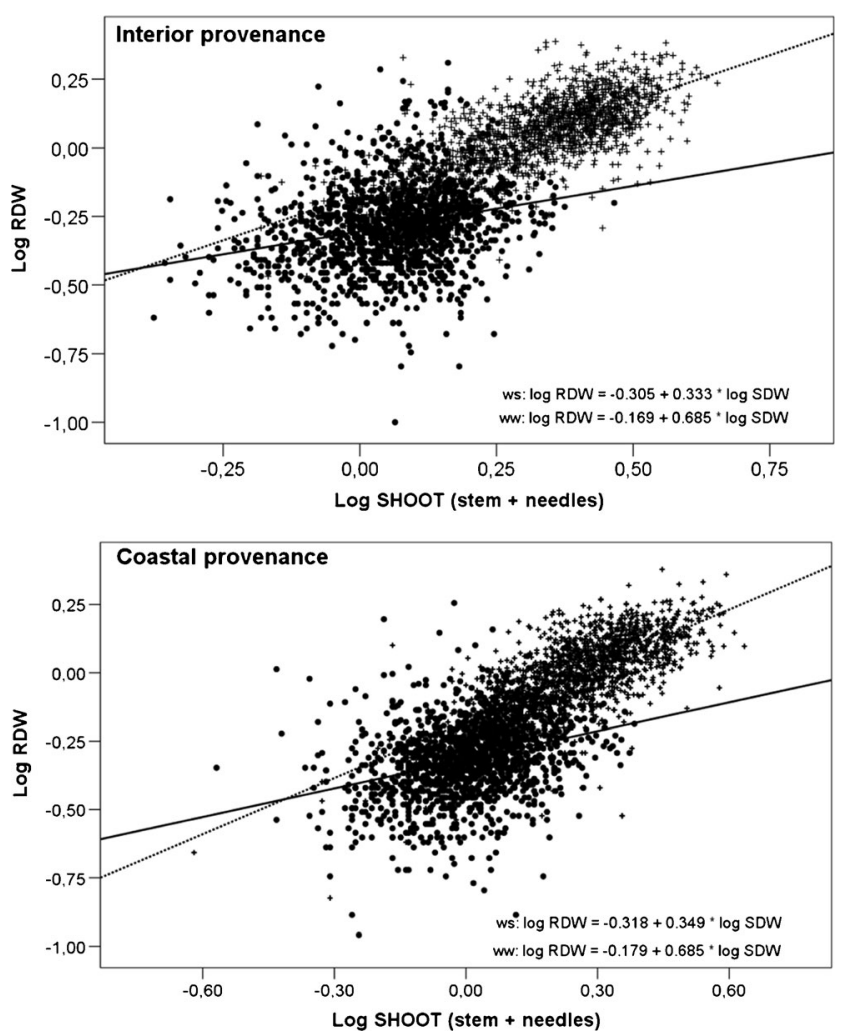

Fig. 2 Effects of water treatment on the allometric relationship between root and shoot biomass of the interior and coastal provenances of P. radiata studied. Dots and continuous lines represent stressed plants, crosses and dotted lines represent non-stressed plants. Regression lines are shown for water stress (ws) and well water (ww) conditions

provenance responses, both in the short and in the long term. Espinoza et al. (2013) pointed out that a possible explanation for the better response of water stressed plants of the interior provenance is due to the stomatal control. This response could have developed on sites where the water is lost rapidly by infiltration and the evaporative demand of the atmosphere is high, forcing plants to close stomata during most of the day. The result of this is a reduction in the leaf area (i.e., NDW). The smaller leaf area transpires less water, effectively conserving a limited water supply in the soil over a longer period. In the present study, seedlings from interior provenance and from the third breeding generation showed a clear reduction of NDW when exposed to water stress, while the coastal provenance did the opposite, so reduction in leaf area can thus be considered a first line of defense against drought. Plant resistance to drought relies on adaptive strategies based on the presence of structural traits related to reduction of water loss during dry periods (Aroca 2012).

In the context of tree improvement for radiata pine in Chile and based on the findings of Espinoza et al. (2014) who estimated genetic parameters using the same watering treatments and data set of the present study, we argue that the increase in survival and decrease in $H$ in the interior provenance over
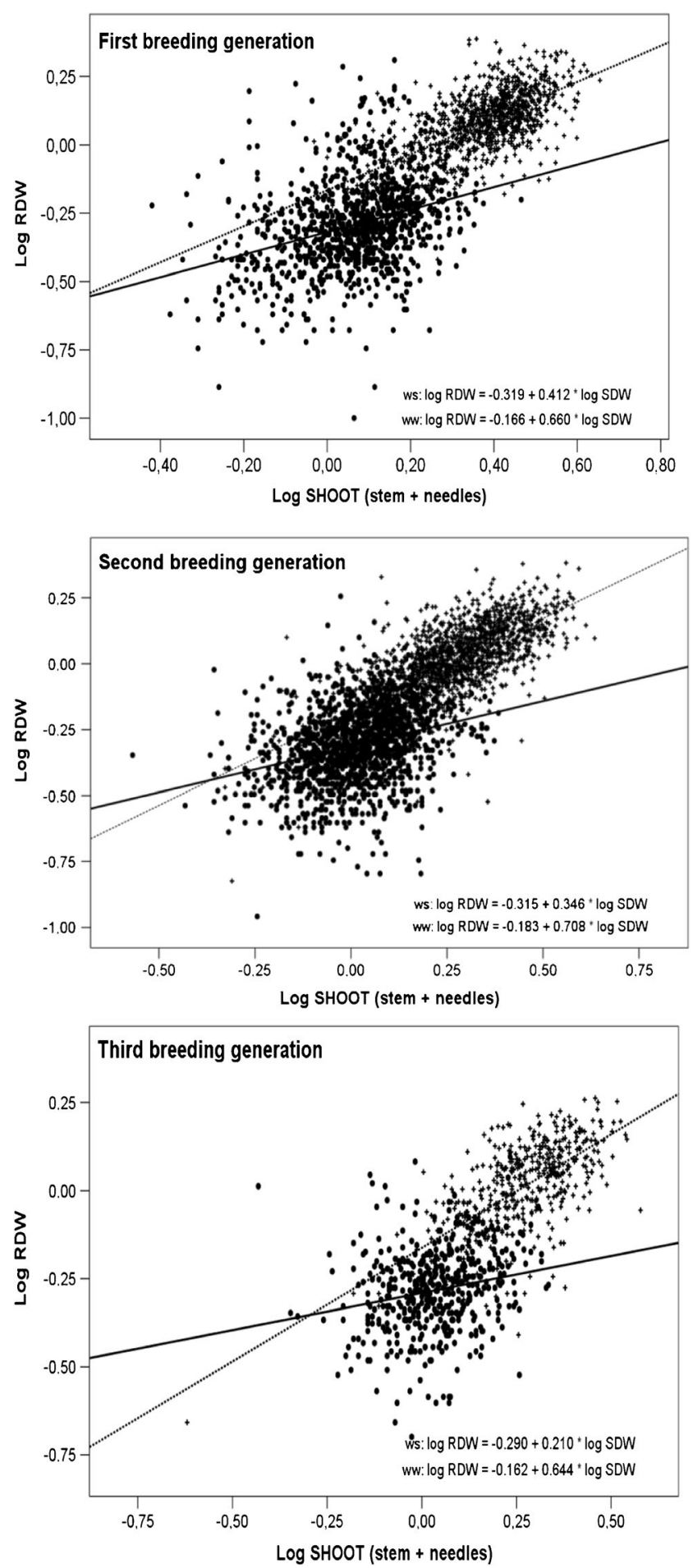

Fig. 3 Effects of water treatment on the allometric relationship between root and shoot biomass of the different breeding generation of $P$. radiata provenances studied. Dots and continuous lines represent stressed plants, crosses and dotted lines represent non-stressed plants. Regression lines are shown for water stress (ws) and well water $(w w)$ conditions

three breeding generations could be attributed to the adverse genetic correlations between both variables $\left(r_{\mathrm{g}}=-0.45\right)$. In breeding programs, genetic correlations are used for predicting how selection for one or several traits will affect 
correlated traits in the next generation. On the other hand Espinoza et al. (2014), similar as reported by Ivković et al. (2009) in a radiata pine field trial in a drought-prone site, found a low but significant narrow sense heritability $\left(h^{2}=\right.$ 0.14 ) for survival in interior provenance when faced drought; thus, both genetic correlations and heritability allow us to speculate that breeding and adaptation to the exposed interior environment involves genetic changes that are heritable to the next generation, and have allowed interior provenance to increase survival and drought tolerance.

\subsection{Effects of water stress on biomass allocation}

Changes in biomass allocation have been extensively studied in different species facing drought, with contradictory results. According to Poorter et al. (2012a), when plants are subjected to severe drought (i.e., when biomass is reduced by $>50 \%$ of that of control plants), there is a strong increase in roots at the expense of stems. In this sense, Aspelmeier and Leuschner (2006) reported a reduction of overall shoot growth compared to root growth in silver birch, while Chambel et al. (2007) observed a shift in the biomass allocation to the shoots at the expense of the roots, independent of plant size (i.e., changes in the allometric trajectories of Pinus pinaster, P. halepensis, $P$. canariensis, and P. pinea) induced by the water stress.

The results of the present study show that exposures to water shortage induced changes in the pattern of biomass allocation in young radiata pine seedlings, which depended on the provenance and breeding generation. The imposed water shortage caused a reduction of biomass, growth, and survival relative to the unstressed treatment. There were notable differences between the analyses of biomass ratios and the allometric analyses. Overall, the influence of water availability on biomass allocation patterns, as represented by RSR, a useful trait when selecting clones for drier environments (Grossnickle 2000), was not pronounced and goes contrary to the optimal partitioning theory (OPT) (Table 3), but in our allometric analyses, the watering effects appeared (Fig. 2 and Fig. 3). This could indicate that many of the strong linkages between growth and biomass traits could be attributable to allometric partitioning theory (APT) as the primary regulatory form of biomass partitioning, especially in the coastal provenance.

If the variation in organ mass distribution demonstrates OPT, then stem and leaf mass variation should be positively related to water availability while the root mass residuals should show the opposite pattern. In this study, seedlings from coastal provenance seems to follow an APT because this theory is based on the constraints of maximizing photosynthetic harvesting capacity and resource transport, while minimizing hydrodynamic resistance and transport times (McCarthy and Enquist 2007). Seedlings from this provenance have a superior NDW (photosynthesis) and SDW (transport), both in the well-watered and water stress treatments, which could be the reason of the rapid depletion of water in the water shortage treatment and could explain the differences in survival.

\section{Conclusions}

P. radiata is a species which exhibits high degree of differentiation among provenances. Our study showed differences among provenances and breeding generations in survival, growth, and biomass allocation when subjected to water shortage at the seedling stage. This would point out to different strategies among provenances, particularly for water use. Genotypes from the interior provenance were found to increase its degree of drought tolerance with breeding generation. They increased their survival from first to third generation. These changes could be attributed to the negative genetic correlations reported between growth and survival. Also, these genotypes have adapted successfully to sites with periodic drought, showing a superior survival and a more conservative strategy of water use (i.e., increasing deeper water extraction by allocating more biomass to the roots and decreasing transpiration rate by allocating less biomass to the shoots), when passing from one breeding generation to the next. This may be because interior provenance had already been subjected to selection and adaptation towards local conditions in sandy soil sites characterized by low water holding capacity and higher deficit pressure vapor.

Acknowledgments We gratefully acknowledge Dr. Verónica Emhart from Forestal Mininco S.A. for supplying the seeds to carry out this experiment. Special thanks to two reviewers for valuable comments and improvements to the early version of this manuscript, Dr. Hendrik Poorter from Forschungszentrum Jülich and Dr. Frank Telewski from the Michigan State University.

Funding This research was funded by the National Fund for Scientific and Technological Development (FONDECYT) from the National Commission for Scientific and Technological Research (CONYCIT) (Initiation into Research Project No. 11121484 "Identification of Pinus radiata D. Don families suitable to be established in dry land areas").

\section{References}

Albert F (1900) Las Dunas O Sean Las Arenas Volantes, Voladeros, Arenas Muertas, Invasión de las Arenas, Playas I Médanos del Centro de Chile. Comprendiendo el Litoral Desde el Norte de la Provincia del Aconcagua Hasta el Límite Sur de la de Arauco. Santiago, Chile. Cervantes

Aroca R (2012) Plant responses to drought stress. From morphological to molecular features. Springer, Berlin Heidelberg

Aspelmeier S, Leuschner C (2006) Genotypic variation in drought response of silver birch (Betula pendula Roth): leaf and root morphology and carbon partitioning. Trees 20:42-52

Bouffier L, Raffin A, Rozenberg P, Meredieu C, Kremer A (2009) What are the consequences of growth selection on wood density in the 
French maritime pine breeding programme? Tree Genet Genomes 5: $11-25$

Camus P (2006) Ambiente, bosques y gestión forestal en Chile 15412005. Diban LOM, Santiago, Chile

CONAMA (2006) Estudio de la variabilidad climática en chile para el Siglo XXI. Informe Final. Departamento de Geofísica, Facultad de Ciencias Físicas y Matemáticas. Universidad de Chile, Chile

Cown DJ, Young GD, Burdon RD (1992) Variation in wood characteristics of 20-year-old half-sib families of Pinus radiata. N Z J For Sci 22:63-76

Chambel MR, Climent J, Alía R (2007) Divergence among species and populations of Mediterranean pines in biomass allocation of seedlings grown under two watering regimes. Ann For Sci 64:87-97

Espinoza S, Magni C, Martínez V, Ivković M (2013) The effect of water availability on plastic responses and biomass allocation in early growth traits of Pinus radiata D. Don. Forest Syst 22:3-4

Espinoza S, Martínez V, Magni C, Ivković M, Santelices R, Guerra F, Cabrera A (2014) Genetic control of growth, biomass allocation and survival under drought stress in Pinus radiata D. Don seedlings. Tree Genet Genomes. doi:10.1007/s11295-014-0741-1

Falster DS, Warton DI, Wright IJ (2003) (S) MATR: Standardised Major Axis Tests and Routines, Version 1.0. http://www.bio.mq.edu.au/ ecology/SMATR. Accessed 02 Apr 2014

Grossnickle SC (2000) Ecophysiology of northern spruce species: the performance of planted seedlings. NRC Press, Ottawa

Heth D, Kramer PJ (1975) Drought tolerance of pine seedlings under various climatic conditions. For Sci 21:72-82

Huber A, Trecaman R (2002) Efecto de la variabilidad interanual de las precipitaciones sobre el desarrollo de plantaciones de Pinus radiata (D. Don) en la zona de los arenales VIII Región, Chile. Bosque 23: 43-49

Ivković M, Baltunis B, Gapare W, Wharton T, Elms S, Sasse J, Dutkowski G, Powell M, McRae T, Wu H (2009) Breeding radiata pine to maximise profits by incorporating risk traits. Forest \& Wood Products Australia. Project Number: PNC069-0708

Klinkhamer PGL, Jong TJD, Meelis E (1990) How to test for proportionality in the reproductive effort of plants. Am Nat 135:291-300
Lewis NB, Ferguson IS (1993) Management of radiata pine. In: Sutton WR, Donald DMG, Lisboa HB (eds) The Chilean radiata pine sector. Inkata Press, Melbourne, Australia, pp 365-379

Li L, Wu HX (2005) Efficiency of early selection for rotation-aged growth and wood density traits in Pinus radiata. Can J For Res 35:2019-2029

McCarthy MC, Enquist BJ (2007) Consistency between an allometric approach and optimal partitioning theory in global patterns of plant biomass allocation. Funct Ecol 21:713-720

Mead DJ (2013) Sustainable management of Pinus radiata plantations. FAO Forestry Paper No. 170. Rome, Italy

Pearsall WH (1927) Growth studies: VI. On the relative sizes of growing plant organs. Ann Bot 3:549-556

Pigliucci M, Murren CJ, Schlichting CD (2006) Phenotypic plasticity and evolution by genetic assimilation. J Exp Biol 209:2362-2367

Poorter H, Nagel O (2000) The role of biomass allocation in the growth response of plants to different levels of light, $\mathrm{CO}_{2}$, nutrients and water: a quantitative review. Aust J Plant Physiol 27:595-607

Poorter H, Niklas KJ, Reich PB, Oleksyn J, Poot P, Mommer L (2012a) Biomass allocation to leaves, stems and roots: meta-analyses of interspecific variation and environmental control. New Phytol 193: $30-50$

Poorter H, Fiorani F, Stitt M, Schurr U, Finck A, Gibon Y, Usadel B, Munns R, Atkin OK, Tardieu F, Pons LJ (2012b) The art of growing plants for experimental purposes: a practical guide for the plant biologist. Funct Plant Biol 39:821-838

SAS Institute (1999) SAS/STAT ${ }^{\circledR}$ user's guide, version 8. SAS Institute Inc., Cary, NC

Samson DA, Werk KS (1986) Size-dependent effects in the analysis of reproductive effort in plants. Am Nat 127:667-680

Schlichting CD (2004) The role of phenotypic plasticity in diversification. In: DeWitt TJ, Scheiner SM (eds) Phenotypic plasticity: functional and conceptual approaches. Oxford University Press, Oxford, pp 191-200

Schlichting CD, Pigliucci M (1998) Phenotypic evolution-a reaction norm perspective. Sinauer Associates, Sunderland, MA

Zobel B, Talbert J (1984) Applied forest tree improvement. John Wiley \& Sons, USA 